Revista Verde de Agroecologia e Desenvolvimento Sustentável

http://www.gvaa.com.br/revista/index.php/RVADS

REVISÃO BIBLIOGRÁFICA

DOI: http://dx.doi.org/10.18378/rvads.v10i5.3536

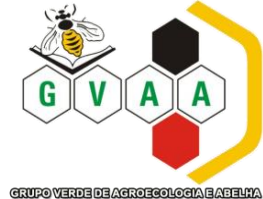

\title{
Integração soja e pastagem: Uma revisão de literatura
}

\section{Integrating soybean and pasture: A literature review}

\author{
Jeandson Silva Viana ${ }^{2}$, Jesimiel Gomes Barbosa ${ }^{1}$, José Alexandre da Silva ${ }^{1}$, Thyago Rodrigues do Carmo Brito ${ }^{1 *}$, César \\ Auguste Badji
}

Resumo: A necessidade do aumento de produção de alimentos de forma sustentável se faz cada vez mais presente. Neste aspecto, a soja (Glycine max (L.) Merrill) e a carne bovina são a base da alimentação mundial por serem fontes ricas em óleo e proteínas. No entanto, o cultivo convencional de soja e as pastagens extensivas não atende esses aspectos, principalmente quando relacionado à minimização dos impactos sobre o meio ambiente. A integração lavoura - pecuária é uma solução viável para esta problemática, pois apresenta resultados positivos para produção de grãos de soja e para as pastagens, por meio do aumento da qualidade do solo, ciclagem de nutrientes, conservação da umidade, preparo único do solo, controle de plantas daninhas, interrompendo ciclos de insetos e doenças. Objetivou-se com esse trabalho apresentar a importância da soja para sistemas de integração lavoura-pecuária.

Palavras-chave: Glycine max, ciclagem de nutrientes, pastagens, lavoura - pecuária.

Abstract: The needs for increasing the production of food in a sustainable way are more and more present nowadays. Regarding this, soybean (Glycine max (L.) Merrill) and beef are the basis of global feed, because they are rich sources of protein and oil. However, the conventional growing of soy and the extensive pasturing do not meet these aspects, particularly when related to the minimization of their impacts on the environment. The integrated crop-livestock is a viable solution for such problem once it shows positive results for both the production of soybeans and pastures, by increasing soil quality, nutrient cycling, dampness conservation, single soil preparation, weed control, by interrupting insect cycles and diseases. Objective of this paper was to present the importance of soybeans for crop-livestock systems.

Key words: Glycine $\max (\mathrm{L}$.$) Merrill, nutrient cycling, pastures, crop-livestock.$

\footnotetext{
*Autor para correspondência

Recebido para publicação em 31/07/2015; aprovado em 22/12/2015

${ }^{1}$ Mestrandos em Produção Agrícola, Universidade Federal Rural de Pernambuco - Unidade Acadêmica de Garanhuns; (87) 9147-9349. E-mail: jesimielgb@live.com, alexan799@gmail.com, thyagorodrigues@agronomo.eng.br*

${ }^{2}$ Docentes do PPG em Produção Agrícola, Universidade Federal Rural de Pernambuco - Unidade Acadêmica de Garanhuns. E-mail: jeandson@uag.ufrpe.br, cabadji@uag.ufrpe.br
} 


\section{INTRODUÇÃO}

Em um contexto global, a agricultura vem enfrentando diversos desafios para se produzir alimentos em maior quantidade e de qualidade, tais como outros derivados, a exemplo, fibras, energia minimizando os impactos sobre o meio ambiente, bem como realizar uma agricultura de baixo carbono, que emite menos gases na atmosfera causadores do efeito estufa (FOLEY et al., 2005).

A produção alimentar do mundo é novamente fonte de preocupação para autoridades mundiais, a degradação generalizada e o aprofundamento da escassez dos recursos do solo e da água colocaram em risco vários sistemas essenciais de produção alimentar no mundo, aponta de um novo relatório da FAO fornecer, pela primeira vez, uma avaliação global do estado dos recursos dos solos do planeta: $25 \%$ estão degradados. Segundo o documento, a degradação e a escassez dos solos e da água impõem um novo desafio à tarefa de alimentar uma população mundial que deve chegar a 9 bilhões de pessoas em 2050 (FAO, 2015).

A FAO estima que esse aumento da população e dos rendimentos vai exigir um aumento de $70 \%$ na produção global de alimentos. Isso equivale a mais de um bilhão de toneladas de cereais e 200 milhões de toneladas de produtos animais produzidos a cada ano (FAO, 2015).

Neste sentido, o Brasil é de grande importância por ser um dos maiores exportadores mundiais de produtos agrícolas e alimentares (BARONA et al., 2010). O País também figura no seleto grupo dos grandes produtores de proteína vegetal e animal. Nos últimos tempos, devido ao aumento da população e poder de compra dos consumidores, observa-se uma demanda cada vez maior, tanto no consumo interno quanto externo, com grande destaque para a soja e a carne bovina brasileira.

Contudo, esta revisão se faz necessária, tendo em vista que grande parte produção de carne bovina no Brasil provém de sistemas extensivos que apresentam baixíssima produtividade devido o manejo inadequado e demandam extensas áreas para a criação dos animais, acarretando no esgotamento do sistema e elevando o grau de degradação do meio. Com isso, a integração com a soja se torna uma opção essencial se considerarmos que esta leguminosa fixa $\mathrm{N}$ no solo, sendo que este elemento é o mais requerido pelas gramíneas para se obter uma alta produção de biomassa que, por conseguinte, beneficia o rebanho bovino. Ademais, favorece a ciclagem de nutrientes, protege o solo com a cobertura vegetal presente durante a entressafra e diversifica a produção durante todo $\mathrm{o}$ ano, assim, minimizando a sazonalidade.

Desta forma, objetivou-se com esse trabalho apresentar a importância da soja para sistemas de integração lavourapecuária.

\section{METODOLOGIA}

A revisão foi realizada como parte das atividades da disciplina Sistemas Locais de Produção Agrícola, da PósGraduação em Produção Agrícola, da Unidade Acadêmica de Garanhuns, Universidade Federal Rural de Pernambuco. Foram pesquisados artigos nacionais e internacionais que abordam o tema, com os principais resultados e conclusões.

\section{REVISÃO}

\section{SOJA (Glycine max (L.) Merrill)}

A soja pertence à família Fabaceae e possui posição privilegiada entre as leguminosas, uma vez que seu grão é fonte de proteína e óleo, para os seres humanos, animais e diversos produtos industriais, tendo assim grande aplicabilidade na indústria e no consumo com a produção total de grãos de aproximadamente 318,25 milhões de toneladas em todo o mundo (USDA, 2015).

O Brasil é um grande produtor e exportador desta cultura que já está plenamente adaptada as nossas condições devido ao avanço tecnológico das últimas décadas e aos programas de melhoramento.

Tendo em vista a rápida expansão das lavouras, sobretudo, no cerrado brasileiro, esta cultura vem ocupando áreas antes inexploradas ano após ano (ANDRADE, 2010).

A Produtividade de soja do Brasil em 2013/14 estabeleceu um novo recorde de produção, atingindo mais de 86 milhões de toneladas, cultivada em cerca de 30 milhões de hectares dedicados a lavouras (CONAB, 2014).

$\mathrm{O}$ último levantamento feito pelo órgão nesta safra de verão (2014/2015) apontam um patamar nunca antes alcançado, com produção de 95 milhões de toneladas da oleaginosa e uma área plantada de 31,5 milhões de hectares (incremento de 1,4 milhão de hectare em relação à safra 2013/2014). Contudo, à maior produção está diretamente ligada ao aumento da produtividade nas lavouras brasileiras, que na safra 2013/2014 foram de $2.854 \mathrm{~kg} / \mathrm{ha}$ (ou 47,56 sc/ha) sendo que nesta safra 2014/2015 giram entorno de 3.011 $\mathrm{kg} / \mathrm{ha}$ (ou 50,18 sc/ha) (CONAB, 2015).

Neste cenário de crescimento, o MATOPIBA, enclave de cerrado dos estados do Maranhão, Tocantins, Piauí e Bahia despontam como a última fronteira agrícola com potencial a ser explorada e que hoje já é uma realidade na produção de grãos, sobretudo soja. Este celeiro de grãos contribuiu nesta safra 2014/2015 com um percentual de $10,9 \%$ sobre a produção nacional de soja (CONAB, 2015).

A soja contribuiu nas exportações brasileiras com uma participação significativa nos últimos 10 anos para a balança comercial, correspondendo, em média, com $6 \%$ do total exportado (CONTRADE, 2014). Em contrapartida, a importação desta caiu consideravelmente neste período avaliado, sendo assim, gerando divisas para o país.

\section{INTEGRAÇÃO LAVOURA - PECUÁRIA}

De acordo com um relatório publicado pelo departamento de agricultura dos Estados Unidos (USDA, 2014), o Brasil possui em torno 208 milhões de cabeças de gado, que o torna o segundo maior rebanho bovino do mundo, somente estando atrás do rebanho da Índia. Ademais, isto equivale de $20,1 \%$ do rebanho mundial.

A criação de bovinos no Brasil se dá predominantemente a campo, isto é, produzido em áreas destinadas à pecuária extensiva, com base em forrageiras tropicais que são a base de quase todo o volumoso consumido na dieta. Contudo, grande parte dessas áreas de pastagens extensivas no Brasil apresentam algum grau ou estádio de degradação, uma vez que o manejo adotado empregado é inadequado. Logo, podemos citar o baixo nível tecnológico empregado, ausência de corretivos de solo na cultura ou a não reposição dos nutrientes do solo, necessários para a expressão máxima do potencial genético da forrageira, ocasionando uma 
baixa produção de matéria seca por hectare. Ademais, é comum o uso de uma taxa de lotação inadequada nas pastagens extensivas. Por fim, Balbinot Junior et al. (2009) atenta sobre a baixa oferta de forragem na época de seca (entressafra).

Tendo em vista estes gargalos acima citados, cresce a necessidade de otimização da produção, utilizando novas práticas e manejos que agreguem valor, usando menos insumos e energia dentro do sistema durante todas as estações do ano.

O sistema de integração lavoura-pecuária (SILP) se apresenta como uma alternativa viável e altamente rentável, tendo em vista que diversifica o meio de produção, pois permite a rotação de culturas, além de proteger o solo durante todo $\mathrm{o}$ ano com a cobertura vegetal sempre presente. Ademais, a ciclagem de nutrientes é uma constante neste sistema de produção, pois uma cultura aproveita os resíduos que foram deixados pela sua antecessora, promovendo assim a sustentabilidade dos sistemas com a diversidade no solo, devido ao aumento da atividade dos micro e macro organismos edáficos que contribuem para fertilidade do solo (CARVALHO et al., 2010).

A biomassa dessecada proveniente da forrageira no sistema integrado soja com pastagem funciona como proteção contra o salpicamento das gostas de água da chuva que deslocam as partículas do solo que está diretamente exposto, diminui consideravelmente as perdas de solo, que são carregados após as enxurradas devido a ação do escoamento superficial sobre o solo. Melhora a aeração, taxa de infiltração de água, aumenta a capacidade de troca de cátions e os níveis de carbono no solo.

Franchini et al. (2014), em ensaios com dessecação de Brachiaria ruzizienses em função de diferentes pressões de pastejo bovino em sistema de rotação com a soja, observaram que quanto maior o intervalo entre a dessecação da forrageira e a semeadura da soja, maior é a altura e a densidade de plantas de soja por metro linear, independente do cultivar utilizado, sendo os melhores resultados obtidos quando o pasto foi dessecado a uma altura de $35 \mathrm{~cm}$.

Neste aspecto, Da Silva (2014) observou em seu trabalho "Intensidade de pastagem e presença ou ausência de entrada de esterco de gado e seus relacionamentos com nutrição e produtividade da soja em sistemas de integração lavoura-pecuária sob plantio direto" que a entrada de esterco de gado resultante de animais pastando na fase de pastagem potencializou o rendimento de grãos de soja, tendo como resultado o aumento de $122 \%$ e $38 \%$ a disponibilidade de $\mathrm{K}$ do solo e $\mathrm{P}$, respectivamente, resultante da entrada de esterco, em relação à ausência. Deste modo, o teor de tais nutrientes na planta foram aumentadas em $41 \%$ e $7 \%$, respectivamente. Com essa melhoria na nutrição de soja culminou no acréscimo da quantidade de vagens por planta em $20 \%$, e resultando em um aumento de $23 \%$ na produtividade da soja.

A rotação de culturas e a diversidade nos meios de produção ajudam a quebrar os ciclo de diversas plantas espontâneas, pragas e patógenos incidentes, extremamente nocivos às culturas agrícolas, que representam atualmente os principais fatores de perdas econômicas neste segmento de produção (MACHADO; VALLE, 2011). Como vantagem, também pode-se citar uma maior qualidade da forragem produzida em um sistema integrado com lavoura. Logo, a forragem possui um maior índice de área foliar, maior valor nutritivo, maior produção de biomassa seca e menor incidência de plantas infestantes no estande da cultura.

Portanto, um dos principais objetivos de integrar a soja é amortizar os custos resultantes da recuperação das áreas de pastagem degradada com o advento da produção dos grãos. Além do mais, a correção do $\mathrm{pH}$ do solo e a adubação da lavoura recupera, em partes, a fertilidade perdida nos anos de pasto extensivo que, geralmente, eram mantidos apenas pela matéria orgânica. Moreira e Siqueira (2006) afirmam que a condição de solos ácidos prejudica drasticamente as atividades na rizosfera de organismos benéficos às culturas. Outro ponto negativo dos solos ácidos é a baixa disponibilidade dos nutrientes na solução do solo e o efeito tóxico dos elementos (SORATTO; CRUCIOL, 2008), principalmente o alumínio $\left(\mathrm{Al}^{3+}\right)$.

Esta revisão visou verbalizar a importância da adoção da integração Soja X Pastagem para a diversificação das atividades, o aumento de produtividade, dos lucros obtidos e da sustentabilidade do agrossistema, uma vez que minimiza os impactos ambientais decorrentes da produção agrícola com o uso eficiente dos insumos e do solo em questão.

O sistema de integração lavoura-pecuária (SILP) tem melhor desempenho em termos de produção de carne bovina, devido aos efeitos positivos da rotação entre produção agrícola e pecuária. Portanto, de acordo com Salton et al. (2014) os resultados da pesquisa "Sistema de integração lavoura-pecuária no Brasil tropical: Rumo a um sistema de produção sustentável" confirmam a hipótese inicial e indicam que SILP é um sistema de gestão apropriado na área de estudo. Este sistema tem um desempenho melhor do que os outros sistemas estudados em termos de qualidade e produtividade do ambiente, garantindo a sustentabilidade da atividade agrícola. O SILP apresentou desempenho melhor do que o pasto permanente (PP), com ganhos de $8,7 \%$ na produtividade por animal e $12,9 \%$ na produtividade por área. Em anos com a distribuição de chuvas ruim, com déficits hídricos, o SILP e o plantio direto (SPD) exibiram perdas de produtividade menores em comparação com sistema convencional (SC). Na safra 2010/11, por exemplo, o SC produziu apenas $60 \%$ de produção das colheitas obtidas de outros sistemas (SILP e SPD).

Segundo Perreira Filho (2003), Nos cerrados, o milheto Pennisetum glaucum (L) é uma gramínea que vem apresentando bons resultados como alta produção de biomassa no período da seca ( 9 ton.ha $\left.{ }^{-1}\right)$. Podendo ser uma excelente fonte de volumoso aos animais. Sua semeadura (10 a $20 \mathrm{~kg} / \mathrm{ha} / \mathrm{semente}$ deve ser feita no terço final das chuvas ou mesmo imediatamente após a colheita da Soja. As gramínineas do gênero Brachiaria (Cv. Marandú, Ruzizienses, Decubens) e Panicum (Mombaça) também são recomendadas na integração com a lavoura, contudo, deve-se atentar a média/alta fertilidade do solo exigida pelas gramíneas do gênero Panicum para o seu estabelecimento. A semeadura de ambos os gêneros também deve ser feita logo após a colheita da soja. Como vantagem, a dessecação da biomassa dessas gramíneas após o período de pastejo e início da próxima safra propicia condições favoráveis a disponibilidade e armazenamento de água no solo, fator este essencial para a soja em condições de veranico.

Franchini et al. (2014), em ensaios no noroeste paranaense com a integração lavoura pecuária floresta (ILPF), observaram que a espécie de eucalipto Corymbia maculata (Eucalyptus maculata Hook) não interferiu no rendimento da 
soja nos dois primeiros anos de avaliação após a instalação do experimento, tampouco na produção de massa seca de Brachiaria ruzizienses nessa época. Porém, a partir desse período, houve um decréscimo de produtividade nessas duas últimas culturas, muito provavelmente pelo arranjo do sistema, ocasionando sombreamento e efeito alelopático.

É sabido que a integração lavoura pecuária otimiza o sistema de plantio direto e representa uma alternativa na recuperação de áreas degradadas em solos tropicais e preserva os solos, entretanto, o manejo dos animais e a taxa de lotação na área deve ser apropriado, pois, os efeitos do pisoteio ao solo podem ser danosos devido a compactação (SOUZA et al., 2010).

A compactação do solo, seja ela ocasionada pelo trânsito de máquinas ou animais é bastante danoso ao agrossistema, pois reduz consideravelmente a produtividade, inibe $\mathrm{o}$ desenvolvimento radicular das plantas e por conseguinte a absorção de água e nutrientes.

Se tratando em produção de grãos no Brasil em escala comercial, há predominância do sistema de plantio direto (SPD), que consiste numa produção de biomassa vegetal para proteger o solo da exposição direta durante o período da entressafra, contribuindo para o ciclo biogeoquímico das culturas envolvidas no sistema. Partindo desse princípio, a integração soja x pastagem é bastante vantajosa, pois garante uma renda extra para o produtor e uma eficiência de produção acima da grande maioria das propriedades brasileiras.

\section{CONSIDERAÇÕES FINAIS}

O estádio atual de degradação (em média 80\%) da pecuária extensiva brasileira é bastante preocupante, logo, os baixíssimos índices de produtividade, em média, 0,75 Unidade Animal (U.A) por hectare não se sustenta.

A integração lavoura pecuária é uma importante alternativa de manejo para a agropecuária nacional, uma vez que permite um uso racional e inteligente dos insumos agrícolas, minimiza os impactos ambientais decorrentes do monocultivo em larga escala a curto, médio e longo prazo, além de diversificar a produção agrícola agregando valor e amenizar o efeito da sazonalidade na atividade agropecuária.

A soja por ser uma commodity de alto valor de mercado e de grande poder de captura do $\mathrm{N}$ atmosférico para a planta e solo é uma ótima opção para o produtor no manejo. Se levarmos em consideração que o $\mathrm{N}$ é o nutriente requerido em maiores quantidades pelas forrageiras e que exige maior reposição devido à sua dinâmica no solo, além do mais os fertilizantes nitrogenados são predominantemente importados e cotados em dólar, isto representaria uma grande economia nos custos de implantação e manutenção das pastagens.

Contudo, as características edafoclimáticas e de relevo devem ser levadas em consideração na inserção da soja no sistema de integração lavoura pecuária. Principalmente em solos acidentados, a produtividade da cultura, as perdas de solo e a mecanização são extremamente prejudicados, sendo assim, inviável agronomicamente e economicamente a sua adoção no manejo. Portanto, recomenda-se a substituição por outra leguminosa que melhor se adapte ao ambiente a ser implantado o agrossistema.

\section{REFERÊNCIAS}

ANDRADE, F. M.; HAMAWAKI, O. T.; REZENDE, D. F.; SOUSA, L. B. Genótipos de soja em quatro épocas de semeadura e populações de plantas, em Uberlândia MG. Revista Verde (Mossoró - RN - Brasil) v.5, n.4, 2010 , p. $124-129$.

BALBINOT JUNIOR, A.A.; MORAES, A.; VEIGA, M.; PELISSARI, A. \& DIECKOW, J. Integração lavourapecuária: intensificação de uso de áreas agrícolas. Ci. Rural, 39:1925-1933, 2009.

BARONA, E.; RAMANKUTTY, N.; HYMAN, G.; COOMES, O. T. The role of pasture and soybean in deforestation of the Brazilian Amazon. Environmental Research Letters. U.K., v. 5, n. 2. P.1-9, 2010.

CARVALHO, P. F. C.; ANGHINONI, I.; MORAES, A.; SOUZA, E. D.; SULC, R. M.; LANG, C. R.; FLORES, J. P. C.; TERRA-LOPES, M. L.; SILVA, J. L. S; CONTE, O.; WESP, C. L.; LEVIEN, R.; FONTANELI, R. S.; BAYER, C. Managing grazing animals to achieve nutrient cycling and soil improvement in no-till integrated systems. Nutrient Cycling in Agroecosystems, v. 88 , p. $259-273,2010$.

COMTRADE - United Nations Commodity Trade Statistics Database. Statistics Division. Disponível em: < http://comtrade.un.org/db/>. Acesso em: 10/04/2015.

CONAB. Companhia Nacional de Abastecimento. Acompanhamento da safra brasileira de grãos. v.1, Safra 2013/14. n.10, p.1-85, 2014. Disponível em: <http://www.conab.gov.br/OlalaCMS/uploads/arquivos/ 14_07_09_09_36_57_10_levantamento_de_graos_julho _2014.pdf> Acessado em 13 abr. 2015.

CONAB. Companhia Nacional de Abastecimento. Acompanhamento da safra brasileira de grãos. v.2, Safra 2014/15. n.8, p.1-118, 2014. Disponível em: < http://www.conab.gov.br/OlalaCMS/uploads/arquivos/1 5_05_13_08_46_55_boletim_graos_maio_2015.pdf> Acessado em 08 mai. 2015.

DA SILVA, Francine Damian et al. Pasture grazing intensity and presence or absence of cattle dung input and its relationships to soybean nutrition and yield in integrated crop-livestock systems under no-till. European Journal of Agronomy, v. 57, p. 84-91, 2014. Disponível em: <http://dx.doi.org/10.1016/j.eja.2013.10.009> Acessado em 13 abr. 2015.

FAO - Organização das nações Unidas para a Alimentação e a Agricultura. Scarcity and degradation of land and water: growing threat to food security, 2015. Disponível em: <http://www.fao.org/news/story/pt/item/95153/icode/> Acesso em 30 abr. 2015.

FAOSTAT-Organização das Nações Unidas para Agricultura e Alimentação. 2012. Disponível <http://faostat.fao.org> Acesso em 13 abr. 2015. 
FOLEY, J.A. et al. Global consequences of land use. Science, v. 309 , p. $570-574,2005$.

FRANCHINI, J. C.; BALBINOT JR, A. A.; DEBIASI, HENRIQUE.; CONTE, O. Soybean performance as affected by desiccation time of Urochloa ruziziensis and grazing pressures. Revista Ciência Agronômica, v. 45, n. 5 (Especial), p. 999-1005, 2014.

FRANCHINI, J. C.; BALBINOT JR, A. A.; SICHIERI, F. R.; DEBIASI, HENRIQUE.; CONTE, O. Yield of soybean, pasture and wood in integrated crop - livestock - forest system in Northwestern Paraná state, Brazil. Revista Ciência Agronômica, v. 45, n. 5 (Especial), p. 10061013, 2014.

FRANZLUEBBERS, A. J. Integrated crop-livestock systems in the southeastern USA. Agronomy Journal, v. 99, n. 2, p. 361-372, 2007. Disponível: < http://dx.doi.org/10.2134/agronj2006.0076> Acesso em 13 abr. 2015.

MACHADO, L. A. Z.; VALLE, C. B. VALLE. Pesquisa. agropecuária brasileira, v. 46, n. 11, p. 1454-1462, nov. 2011.

MARTINS, Amanda Posselt et al. Amelioration of soil acidity and soybean yield after surface lime reapplication to a long-term no-till integrated croplivestock system under varying grazing intensities. Soil and Tillage Research, v. 144, p. 141-149, 2014. Disponível

em: http://dx.doi.org/10.1016/j.still.2014.07.019 Acesso abr. 13. 2015

MENDES, I. C.; HUNGRIA, M.; VARGAS, M. A. T. Soybean response to starter nitrogen and Bradyrhizobium inoculation on a Cerrado Oxisol under no-tillage and conventional tillage systems. Revista Brasileira de Ciência do Solo, v. 27, n. 1, p. 81-87, 2003. Disponível em: http://dx.doi.org/10.1590/S010006832003000100009 Acesso 13 abr. 2015.

MOREIRA, F.M.S.; SIQUEIRA, J.O. Microbiologia e bioquímica do solo. 2. ed. atual. Ampl. Lavras: UFLA, 2006. 729p.

PEREIRA FILHO, I. A. Manejo da cultura do milheto. Sete Lagoas: Embrapa-CNPMS, 2003. 17 p. (EmbrapaCNPMS. Circular Técnica, 29).

SALTON, J.C., MERCANTE, F.M., TOMAZI, M., ZANATTA, J.A., CONCENC, G., SILVA, W.M., RETORE, M. Integrated crop-livestock system in tropical Brazil: Toward a sustainable production system. Agriculture, Ecosystems and Environment 190 (2014) 70-79.

SORATTO, R.P.; CRUSCIOL, C.A.C. Dolomite and phosphogypsum surface application effects on annual crops nutrition and yield. Agronomy Journal, v.100, p.261-270, 2008.
SOUZA, E. D. et al. Soil aggregation in a crop-livestock integration system under no-tillage. Revista Brasileira de Ciência do Solo, Viçosa, v. 34, n. 4, p. 1365-1374, 2010.

TRACY, Benjamin F.; ZHANG, Yan. Soil compaction, corn yield response, and soil nutrient pool dynamics within an integrated crop-livestock system in Illinois. Crop Science, v. 48, n. 3, p. 1211-1218, 2008. Disponível em: <http://dx.doi.org/10.2135/cropsci2007.07.0390> Acesso em 13 abr. 2015.

USDA. USDA Foreign Agricultural Service. Disponivel em: $<$ http://apps.fas.usda.gov/psdonline/> Acesso em junho de 2015.

USDA. USDA Foreign Agricultural Service. Disponível em http://apps.fas.usda.gov/psdonline/circulars/production.pdf> Acesso em julho de 2015. 